\title{
Innovative biofilm inhibition and anti-microbial behavior of molybdenum sulfide nanostructures generated by microwave- assisted solvothermal route
}

\author{
Nilam Qureshi • Rajendra Patil • Manish Shinde • Govind Umarji • \\ Valerio Causin · Wasudev Gade · Uttam Mulik • Anand Bhalerao • \\ Dinesh P. Amalnerkar
}

Received: 15 April 2014/ Accepted: 8 May 2014/Published online: 4 June 2014

(c) The Author(s) 2014. This article is published with open access at Springerlink.com

\begin{abstract}
The incessant use of antibiotics against infectious diseases has translated into a vicious circle of developing new antibiotic drug and its resistant strains in short period of time due to inherent nature of microorganisms to alter their genes. Many researchers have been trying to formulate inorganic nanoparticles-based antiseptics that may be linked to broad-spectrum activity and far lower propensity to induce microbial resistance than antibiotics. The way-out approaches in this direction are nanomaterials based (1) bactericidal and (2) bacteriostatic activities. We, herein, present hitherto unreported observations on microbial abatement using non-cytotoxic molybdenum disulfide nanostructures (MSNs) which are synthesized using microwave assisted solvothermal route. Inhibition of biofilm formation using MSNs is a unique feature of our study. Furthermore, this study evinces
\end{abstract}

Electronic supplementary material The online version of this article (doi:10.1007/s13204-014-0322-5) contains supplementary material, which is available to authorized users.

N. Qureshi · M. Shinde · G. Umarji · U. Mulik ·

D. P. Amalnerkar $(\square)$

Centre for Materials for Electronics Technology (C-MET),

Panchwati Off Pashan Road, Pune 411008, India

e-mail: amalnerkar@cmet.gov.in; dpa54@yahoo.co.in

R. Patil · W. Gade

Department of Biotechnology, University of Pune,

Ganeshkhind Road, Pune 411007, India

V. Causin

Dipartimento di Scienze Chimiche, Università di Padova, via Marzolo 1, Padua 35131, Italy

A. Bhalerao

College of Engineering, Bharati Vidyapeeth University,

Pune 411043, India antimicrobial mechanism of MSNs by reactive oxygen species (ROS) dependent generation of superoxide anion radical via disruption of cellular functions.

Keywords Biofilm · Antimicrobial $\cdot$ ROS $\cdot$ Molybdenum Sulfide $\cdot$ Solvothermal

\section{Introduction}

Indiscriminate use of antibiotics against infectious diseases is turning out to be a vicious cycle of developing new antibiotic drug and its resistant strains in short time span due to inherent tendency of microbial cells to alter their genes. The origin of the multidrug resistant (MDR) microbes lies in the increased evolutionary selection pressure on microbial population which allows the resistant microbes to survive and the susceptible ones to perish. Antibiotic resistance, therefore, poses a significant healthcare threat. There is an urgent and compelling necessity for making improvements in present methods and develop novel strategies to tackle the situation. Three possible solutions emerging in this context are (1) generic approach for development of conventional and newer antibiotics based MDR drugs. This approach may not be feasible over the longer period as there may be a possibility of bacterial resistance to such drugs. Nevertheless, nanomaterials may prove useful in designing the next two approaches, namely, (2) bactericidal (contemporary) approach of exploitation of inorganic nanoparticles to develop antiseptics that are deadly to microbes and may demonstrate wide-ranging activity and lower prospect to promote microbial resistance. However, many nanoparticles have different degrees of toxicity causing restrictions in their use directly as antibacterial agents (Jones et al. 2004), and (3) 
bacteriostatic approach which is the least explored but is significantly emerging and promising. Under this approach, nanomaterial can be applied as an agent that inhibits the formation of biofilms without actually killing the microbial cells. Biofilm growth can cause infection (Bjarnsholt et al. 2010) and has detrimental effects on various materials and equipments like medical devices, implants, and food-processing equipments, thereby causing enormous economic and health-related damages (Weir et al. 2008).

It may be noted that in the context of drug-resistant strains and ineptness of traditional treatments, the nanomaterial-based approaches do not exert evolutionary pressure on bacteria and hence can be beneficial in the long run. Nanoparticles, especially metallic ones, tend to offer an effective solution for overcoming bacterial resistance (Shinde et al. 2012a). But, metallic nanoparticles have different degrees of cytotoxicity, which restrict their use in antimicrobial drugs. In this explicit perspective, we have stumbled upon the report pertaining to biocompatibility and non-cytotoxicity of molybdenum disulfide nanoparticles (Wu et al. 2011). However, they cannot be claimed as complete antimicrobial package unless and until their capabilities showing profound antimicrobial activity and/or anti-biofilm ability are established.

Molybdenum disulfide belongs to a family of fundamentally and technologically important multifunctional layered materials. It forms sandwich interlayer structure created by S-Mo-S layers, which are loosely bound to each other only by van der Waals forces (Rapoport et al. 2005). Such structures, at the bulk and nanoscale, exhibit a broad array of applications, such as electrochemical hydrogen storage (Chen et al. 2001), cathode material for rechargeable lithium batteries and solar cells (Imanishi et al. 1992; Thomalla and Tributsch 2006), electric transport (Kopnov et al. 2006), useful solid lubricant (Rapoport et al. 2003), an intercalation host (Aharon et al. 2006), and field emission tips (Nemanic et al. 2003). For example, molybdenum disulfide may be an alternative material for next-generation nanoelectronic devices viz., transistor (Radisavljevic et al. 2011) and tandem photovoltaic configurations because its electronic properties are superior to silicon (Li et al. 2005) and its band gap transforms from indirect to direct at nanoscale. So far, nanoscale molybdenum disulfide has been obtained with different morphologies such as hollow micro-tubes and micro-spheres (Afanasiev et al. 2000; Afanasiev and Bezverkhy 2002), amorphous tube-and balllike structures (Peng et al. 2002), nano-wires (Li et al. 2003), randomly stacked layers (Li et al. 2004), etc. for host of applications. However, synthesis of molybdenum disulfide nanostructures (MSNs) using a facile and 'green' technique is still a prime challenge which is certainly advantageous from the standpoint of futuristic nano-biotechnology based (including antimicrobial) applications.
Vide this communication, we present an expedient and 'green' microwave-assisted solvothermal synthesis (Shinde et al. 2012b) of MSNs and hitherto unreported pre-therapeutic antimicrobial application protocol of the same. Fundamentally, the synthesized products were explored for antimicrobial applications with two-pronged intentions: (1) to probe biofilm inhibition (in Psuedomonas aeruginosa 01) which is the earliest assertion of MSNs as anti-biofilm agents and (2) to assay the antibacterial property of synthesized nanoparticles (using model organisms, grampositive Bacillus subtilis NCIM 2063 and gram-negative Escherichia coli NCIM 2931 and corroborate the possible mechanism by detecting and measuring the reactive oxygen species (ROS) and simultaneously monitoring the redox enzymes. Additionally, non-cytotoxic nature exhibited by MSNs in case of Hela cells boosts their scope as antimicrobial material.

\section{Experimental section}

\section{Synthesis of MSNs}

All the reagents were of analytical grade and were used as received without any further purification. In a typical experimental procedure, ammonium molybdate $\left[\left(\mathrm{NH}_{4}\right)_{6} \mathrm{Mo}_{7} \mathrm{O}_{24} \cdot 4 \mathrm{H}_{2} \mathrm{O}\right]$ and elemental sulfur were mixed in $1: 1$ molar ratio in $10 \mathrm{ml}$ hydrazine monohydrate and $30 \mathrm{ml}$ deionized water (DIW) under magnetic stirring for $5 \mathrm{~min}$. The resultant solvent mixture was transferred to Teflon vessel and subjected to microwave radiation of 270 Watt in household microwave oven (Godrej GMC 30E) for $10 \mathrm{~min}$, and subsequently, was allowed to cool down naturally to room temperature. Black precipitate settled at the bottom of the solution was filtered, washed with DI water, diluted hydrochloric acid and ethanol successively and centrifuged to remove the unreacted precursors. The final product was dried in vacuum oven at $50{ }^{\circ} \mathrm{C}$ for $4 \mathrm{~h}$.

\section{Characterization of MSNs}

The resultant samples were extensively characterized for their structural and morphological features by a variety of analytical techniques. Wide angle X-ray diffraction (WAXD) analysis of our sample was accomplished for accurate phase identification by resolving the overlapping peaks using Philips X'Pert PRO Diffractometer. Dynamic light scattering (DLS) measurement was performed using 90Plus zeta sizer (Brookhaven Inc, NY) for measuring the hydrodynamic diameter of MSNs. Field emission scanning electron microscopy (FESEM) was used to image as-prepared molybdenum disulfide sample using HITACHI S-4800. The resultant powder was directly put on the 
conducting carbon sheet without dispersing in any solvent and coated with conducting gold film. High-resolution transmission electron microscopy (HRTEM) was carried out for powder placed on carbon-coated copper grid (using liquid dispersion of MSNs in isopropyl alcohol) using JEOL JSM 2100. MSNs were also characterized by AFM on an Agilent 5500 AFM/SPM microscope under acoustic AC mode using Si probes operating at a resonant frequency of $154 \mathrm{kHz}$. In all the AFM measurements, topography, phase, and amplitude images were obtained. For clarity, only the topographic images were compared and presented.

\section{Antimicrobial activity assay}

\section{Determination of minimum inhibitory concentration (MIC) and minimum bactericidal concentration $(M B C)$}

The as-synthesized MSNs were dispersed as colloidal suspension in sterile distilled water by sonication before testing for antimicrobial activity. All in vitro antimicrobial activity study was performed using Gram positive and negative model organisms viz. Bacillus subtilis NCIM 2063 and Escherichia coli NCIM 2931, respectively. MIC and $\mathrm{MBC}$ are the lowest concentrations (of nanoparticles, in the present case) at which a tested compound, respectively, inhibits growth or kills more than $3 \log (99.9 \%)$ of bacteria. Since the as-synthesized MSNs in Mueller-Hinton $(\mathrm{MH})$ medium form a suspension, rather than solution, $\mathrm{MBC}$ results were recorded by calculating the colonyforming units per milliliter (CFU/ml). In short, 24-well microtiter plates containing one $\mathrm{mL} \mathrm{MH}$ broth (Hi-Media Mumbai, India), with nanoparticles (in the concentration range of $37-1,000 \mu \mathrm{g} / \mathrm{mL}$ ) were inoculated with test strains (final cell density of $5 \times 10^{4} \mathrm{CFU} / \mathrm{ml}$ ) and incubated at $37{ }^{\circ} \mathrm{C}$ for $15 \mathrm{~h}$. The lowest concentration of nanoparticles showing visual growth inhibition was considered as the MIC. The MBC was measured by preparing serial dilutions from the MIC assay and plating the dilutions on $\mathrm{MH}$ agar plates. The data were recorded as survival rates $(\mathrm{CFU} / \mathrm{ml})$, based on $100 \%$ survival for the untreated control. All MIC and $\mathrm{MBC}$ values reported were based on three experimental repeats (Anon. NCCLS, Wayne, PA, 2000).

\section{Biofilm assay}

Psuedomonas aeruginosa PAO1 was grown overnight in Luria Bertaini (LB) medium at $37{ }^{\circ} \mathrm{C}$ with agitation. After growth, the culture was diluted with LB medium (OD600 0.02 ), and $50 \mu \mathrm{L}$ of the diluted culture was added to $950 \mu \mathrm{L}$ of LB medium supplemented with $150 \mu \mathrm{g} / \mathrm{mL}$ of MSNs and was incubated statically for $18 \mathrm{~h}$ at $37{ }^{\circ} \mathrm{C}$ in eight-well glass chamber slide. After incubation, planktonic bacteria were discarded, and the biofilms were washed three times with cacodylate buffer $(\mathrm{CB}, 0.1 \mathrm{M}, \mathrm{pH}$ 7.4). Biofilms formed on glass plates were fixed in $2 \%$ glutaraldehyde using $0.1 \mathrm{M} \mathrm{CB}\left(\mathrm{pH} \mathrm{7.4)}\right.$ for $4 \mathrm{~h}$ at $40{ }^{\circ} \mathrm{C}$. After thorough washing with $\mathrm{CB}$, samples were dehydrated in a series of ethanol solutions (10-100\%). The samples were dried, mounted on aluminum stubs with conductive carbon cement, and finally coated with a gold film for observation under FESEM (Hitachi 4800 SEM at $1.5 \mathrm{kV}$ ) (Liu et al. 2009). For CLSM, after initial through washing, the biofilm was covered with $50 \mu \mathrm{L}$ of $100 \mu \mathrm{g} / \mathrm{ml}$ of dye, concanavalin A, alexaflour 488, and incubated for $30 \mathrm{~min}$ at $4{ }^{\circ} \mathrm{C}$. The biofilm was finally washed with cacodylate buffer of $0.1 \mathrm{M}, \mathrm{pH} 7.4$, and observed under fluorescence microscopy (Zies, Germany) with an excitation of wavelength of $488 \mathrm{~nm}$ and emission at $519 \mathrm{~nm}$ (Applerot et al. 2012). The statistical analysis was also performed using Image Quanta Analysis (Zies, Germany).

\section{Detection, measurement of ROS, and determination of cell morphology}

The ROS generated by the action of MSNs inside the cells were fluorometrically assayed by fluorescence microscopy while its morphology is detected by FESEM. In a typical experimental procedure, the cells of $B$. subtilils and E. coli were grown to mid $\log$ phase $\left(1 \times 10^{7}\right.$ cells $\left./ \mathrm{mL}\right)$ and then treated with $\mathrm{MSNs}\left(\mathrm{MIC}_{50}\right.$ value, i.e., the value where $50 \%$ reduction in the viable cells takes place) for $3 \mathrm{~h}$ at $37{ }^{\circ} \mathrm{C}$ and $150 \mathrm{rpm}$. The cells were collected by centrifugation at $10,000 \mathrm{rpm}$ for $15 \mathrm{~min}$ at $4{ }^{\circ} \mathrm{C}$ (Foucaud et al. 2007).

\section{Fluorescence microscopy}

The cell pellets were washed three times with $0.1 \mathrm{M}$ phosphate buffer (PB) at $\mathrm{pH} 7.4$ and incubated with $25 \mu \mathrm{M}$ DCFH-DA for $30 \mathrm{~min}$. At the end of the incubation, cells were washed with phosphate buffered saline (PBS) again. The fluorescence of $2^{\prime}, 7^{\prime}$-dichlorofluoroscein (DCF), which is the oxidized product of hydrolyzed $2^{\prime}, 7^{\prime}$-dichlorofluoroscein (DCFH, from DCFH-DA by intracellular esterases), was detected by observing the cells under microscope (Zeiss) at $1,000 \times$ magnification and measured with a Varian fluorescence spectrophotometer, using excitation and emission wavelengths of 485 and $530 \mathrm{~nm}$, respectively. The DCF concentration in cells not exposed to nanoparticles was used as a control.

\section{Scanning electron microscopy}

The cell pellets were washed three times with $0.1 \mathrm{M} \mathrm{PB}$ at $\mathrm{pH} 7.4$, and fixed in PB containing $2.5 \%$ glutaraldehyde at $4{ }^{\circ} \mathrm{C}$ for $4 \mathrm{~h}$. After rinsing twice with $\mathrm{PB}$, the pellets were 
dehydrated in ethanol serials $(10,30,50,70,80,90$, and $100 \%, 15$ min per step) and then dried in air.

\section{Extraction of proteins and assay of antioxidant enzymes}

For the extraction of proteins, $300 \mathrm{~mL} \mathrm{MH}$ broth was added to $\mathrm{MIC}_{50}$ value $(0.15 \mathrm{mg} / \mathrm{ml})$ containing MSNs and $5.0 \times 10^{6}$ cells of B. subtilis and incubated till the density reached to mid log phase $(4 \mathrm{~h})$, upon which it was centrifuged at $10,000 \mathrm{rpm}$ for $15 \mathrm{~min}$ at $4{ }^{\circ} \mathrm{C}$. The cell pellets were suspended in cell lysis buffer ( $\mathrm{PB}, 0.1 \mathrm{M}, \mathrm{pH} 7)$ and subjected to sonication $(10 \mathrm{kHz}$ for $8 \mathrm{~min}$ with four intervals of 2 min each) in ice-cold condition $\left(4^{\circ} \mathrm{C}\right)$. The sonicated sample was centrifuged at $15,000 \mathrm{rpm}$ for 30 min at $4{ }^{\circ} \mathrm{C}$ and the resulting supernatant was used for the assay of antioxidant enzymes. The protein extracted without using nanoparticles was used as control. Total SOD activity was assayed by monitoring the inhibition of reduction of nitro blue tetrazolium (NBT). The reaction mixture of $1 \mathrm{ml}$ contained $50 \mathrm{mM}$ potassium phosphate buffer ( $\mathrm{pH} 7.8$ ), $13 \mathrm{mM}$ methionine, $75 \mu \mathrm{M}$ NBT, $2 \mu \mathrm{M}$ riboflavin, $0.1 \mathrm{mM} \mathrm{Na} \mathrm{E}_{2} \mathrm{EDTA}$, and known volume $(\mu \mathrm{L})$ of enzyme extract corresponding to $250 \mu \mathrm{g}$ of proteins (Giannopolitis and Ries 1977). The reaction mixture was illuminated, perpendicularly, for $15 \mathrm{~min}$ under $60 \mathrm{~W}$ fluorescent tubes at a distance of $10 \mathrm{~cm}$. One unit of SOD activity was defined as the amount of enzyme required to cause $50 \%$ inhibition of NBT reduction monitored at $560 \mathrm{~nm}$.

Catalase activity was determined by measuring the consumption of $\mathrm{H}_{2} \mathrm{O}_{2}$ (extinction coefficient 39.4 $\mathrm{mM}^{-1} \mathrm{~cm}^{-1}$ ) at $240 \mathrm{~nm}$ for $1 \mathrm{~min}$ by the method of Aebi. The reaction mixture contained $50 \mathrm{mM}$ potassium phosphate buffer ( $\mathrm{pH} 7.8$ ), $10 \mathrm{mM} \mathrm{H} \mathrm{H}_{2} \mathrm{O}_{2}$, and known volume $(\mu \mathrm{L})$ of the enzyme extract corresponding to $100 \mu \mathrm{g}$ of proteins in $1 \mathrm{ml}$ volume (Aebi 1984).

\section{Cytotoxicity study}

The cytotoxicity of the MSN against HeLa cells was evaluated by observing cells under microscope and determining the metabolic activity by 3-[4,5-dimethylthiazol-2yl]-2,5 diphenyl tetrazolium bromide (MTT) assay. Briefly, cells were seeded into a 96-well culture plate at $2 \times 10^{4}$ cells/well in a $100 \mu \mathrm{L}$ culture medium. After incubation at $37{ }^{\circ} \mathrm{C}$ in a $5 \% \mathrm{CO} 2$ incubator for $24 \mathrm{~h}$, cells were exposed to the $300 \mathrm{ug} / \mathrm{mL}$ of MSN. The cells were incubated for $72 \mathrm{~h}$, followed by the observance of cells morphology under the microscope at $40 \times$ magnification (Ziess, Germany). For MTT assay, cells were washed in $0.1 \mathrm{M}$ PB saline, added with $20 \mathrm{uL}$ of MTT solution $\left(5 \mathrm{mg} \mathrm{mL}^{-1}\right)$, and incubated in dark for $3 \mathrm{~h} .100 \mathrm{uL}$ of DMSO was added to wells and absorbance was recorded at
$550 \mathrm{~nm}$ in microplate reader (Thermo-fisher, USA) and further cultivation for $4 \mathrm{~h}$.

\section{Results and discussion}

MSNs synthesis and physico-chemical characterization

The synthesis of MSNs was carried out via microwaveassisted solvothermal technique reported for other materials (Shinde et al. 2012a). The schematic describing the outline of the work is illustrated in Fig. 1a. Microwave-assisted solvothermal technique qualifies for the energy efficient 'greener' approach by drastically reducing the reaction time ( $\sim 300$ times faster than the conventional method). Microwave radiation penetrates through Teflon vessel and interacts with the solvents directly causing localized heating and thus generates supercritical conditions favorable for nucleation and growth of nanoparticles. Wide angle X-ray diffraction (WAXD) analysis of our sample was accomplished for accurate phase identification by resolving the overlapping peaks using Philips X'Pert PRO Diffractometer (Fig. 1b). The major diffraction peaks are characteristic of hexagonal $\mathrm{MoS}_{2}$ (JCPDS \# 24-0513). The presence of second phase viz. hexagonal $\mathrm{Mo}_{15} \mathrm{~S}_{19}$ is confirmed by standard finger-printing with the reported data (JCPDS \# 40-0936) as minor phase. WAXD results disclose that synthesized powder exhibits symbiotic existence of biphasic compound comprising $\mathrm{MoS}_{2}$ and rarely occurring $\mathrm{Mo}_{15} \mathrm{~S}_{19}$. The diffraction peaks are very wide entailing presence of nanoscale crystallites. The average crystallite size calculated using Scherrer's equation is in the range of $1-3 \mathrm{~nm}$. The lowmagnification TEM image reveals rod-shaped elongated nanoparticles having thickness nearly $10 \mathrm{~nm}$ and length varying from 20 to $40 \mathrm{~nm}$. HRTEM image shows moderate crystalline nature which can be correlated with substantial peak broadening as observed in WAXD (Fig. 1c.).

FESEM images reveal formation of spherical and irregular shaped particles which (Fig. 2a) appeared to be agglomerated and few irregular shaped plate-like structures appear to be stacked one above the other. Sizes of these structures vary from 40 to $150 \mathrm{~nm}$.

The DLS measurements showed an average intensity weighted particle size $\sim 583 \mathrm{~nm}$. The DLS measurement provides the hydrodynamic size and is expected to be larger than the physical size measured by other techniques such as transmission electron microscopy. Moreover, if the sample is non-homogeneous and a few larger sized nanoparticles are present in the sample, the measurement is skewed towards the larger size.

Hence in this case, the particle size of MSNs was significantly larger than obtained by HRTEM. Therefore, particle 
Fig. 1 Synthesis and characterization of MSNs. a Schematic of the strategy for microwave assisted green synthesis of MSNs via generation of supercritical conditions. b WAXD pattern of resultant molybdenum sulfide powder revealing biphasic nature. The dashed trace and continuous line depict the experimental pattern and fitting function, respectively. c HRTEM image of MSNs. (Inset magnified lattice images at various position indicated by red circles)

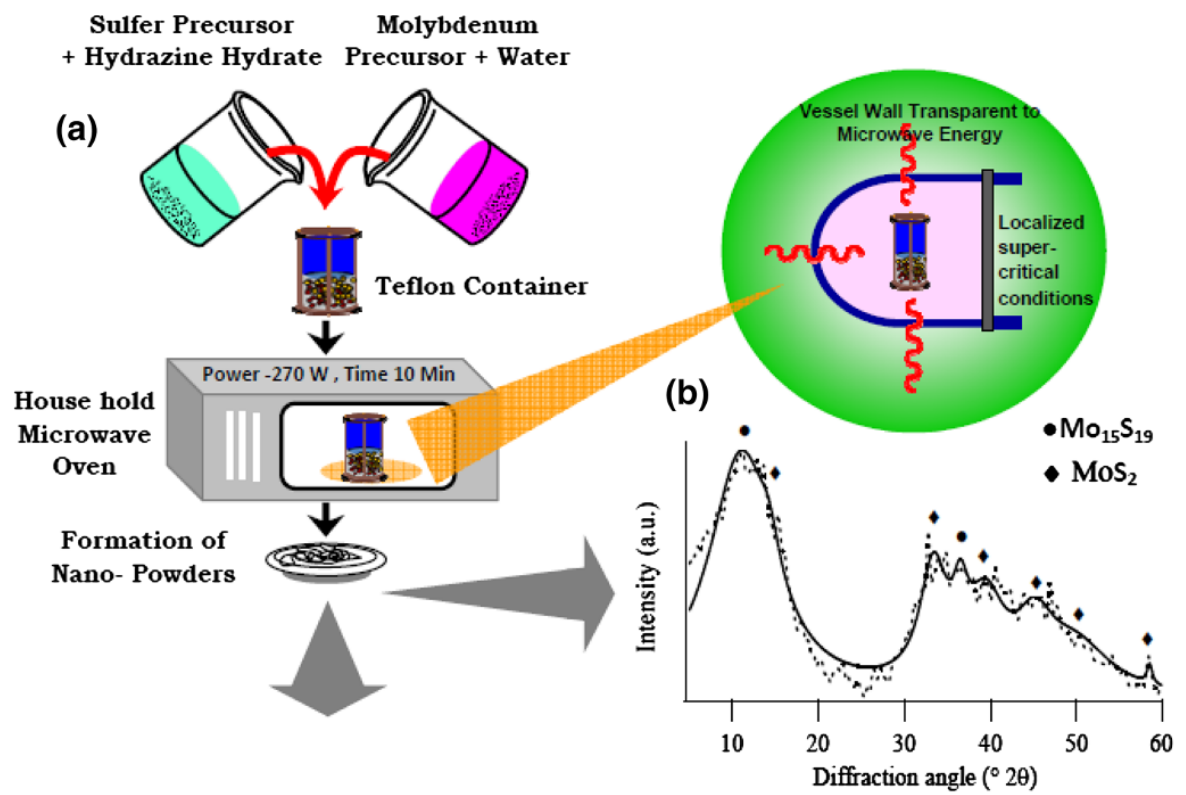

(c)
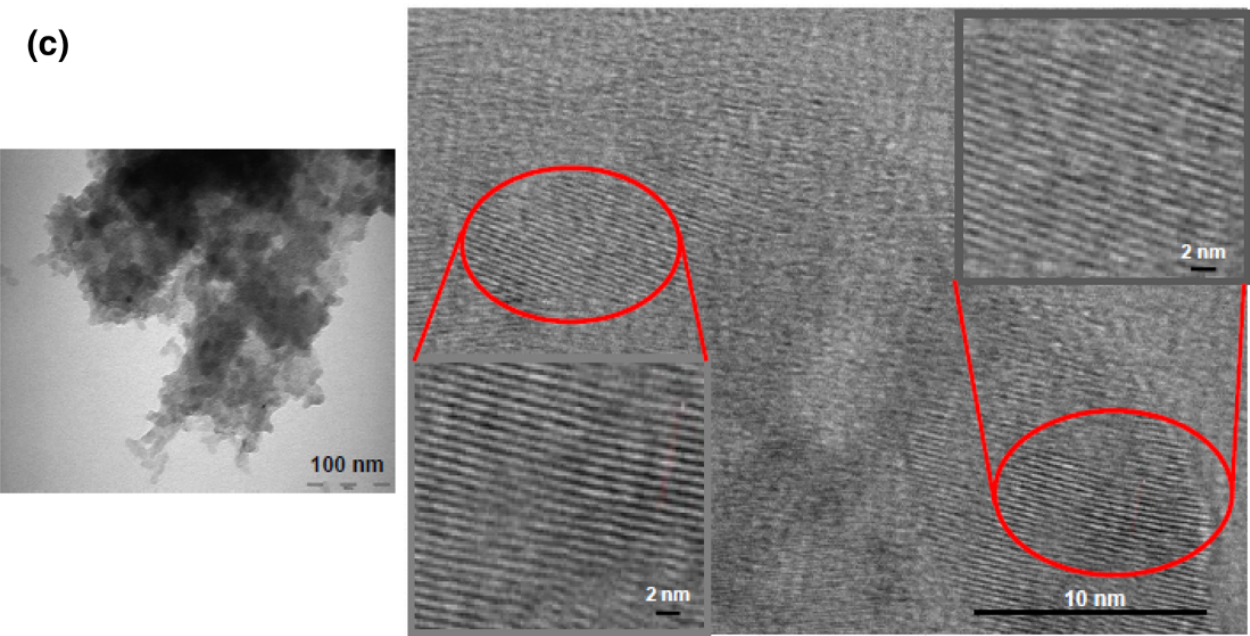

size was measured again after filtering the above samples using a $0.2-\mu \mathrm{m}$ syringe filter. A significant change in the particle size measurement was noted which is reduced to $\sim 155 \mathrm{~nm}$ (Fig. 2b). This size is more consistent with what is expected by TEM measurement. The AFM measurements of MSNs helped to elucidate the morphology along with the size. A representative image in Fig. 2c shows some large aggregated particles in the size range of 200-400 nm.

The height of these particles is in the range of $100 \mathrm{~nm}$. This indicates that these MSNs are not spherical but have a plate-like structure. However, for the $0.5 \times 0.5 \mu \mathrm{m}$ image, several smaller sized nanostructures are seen having size $\sim 20 \mathrm{~nm}$ and average height of $2 \mathrm{~nm}$ (Fig. 2d). The obtained morphology is consistent with the larger sized aggregates in terms of plate-like structure. The AFM results are consistent with the particle size measurement by DLS method.
Biofilm inhibition in $P$. aeruginosa via the effect of MSNs

FESEM analysis of biofilm (corresponding to $P$. aerugin$o s a$ ) treated with our MSNs (at a concentration of $150 \mu \mathrm{g}$ / $\mathrm{mL}$ ) was performed to ascertain its morphological appearance. $P$. aeruginosa was specifically used as a model organism in studying the formation of biofilm on account of its dreadful nuisance in hospitals, particularly, in skin burns. When cells of $P$. aeruginosa were grown in presence of nutrient medium, they adapt to grow, multiply, and communicate with each other by generation of quorum, and upon reaching the critical level density of quorum, they start formation of web-like structure consisting of dense polysaccharides with cells and their debris embedded inside (a biofilm). The free suspended cells are called as planktonic. In sample prepared without MSNs treatment 
Fig. 2 Surface morphology and particle size determination. a FESEM image of resultant $\mathrm{MoS}_{2}$ powder. b DLS particle size measurement of MSNs after filtering using $0.2 \mu \mathrm{m}$ syringe filter. c AFM image of MSNs at low magnification and d representative topographic image at $0.5 \times 0.5 \mu \mathrm{m}$ area image of MSNs
Fig. 3 Biofilm inhibition effect and CSLM analysis.

Representative FESEM image showing effect of MSNs treatment on biofilm inhibition in $P$. aeruginosa. a Control, web-like structure beneath the cells is biofilm and $\mathbf{b}$ MSNs treated, weblike structure is diminished. Under Confocal microscopy, biofilm of $P$. aeruginosa PA 01. c Control, a typical biofilm, and $\mathbf{d}$ MSNs treated, a truncated formation of biofilm
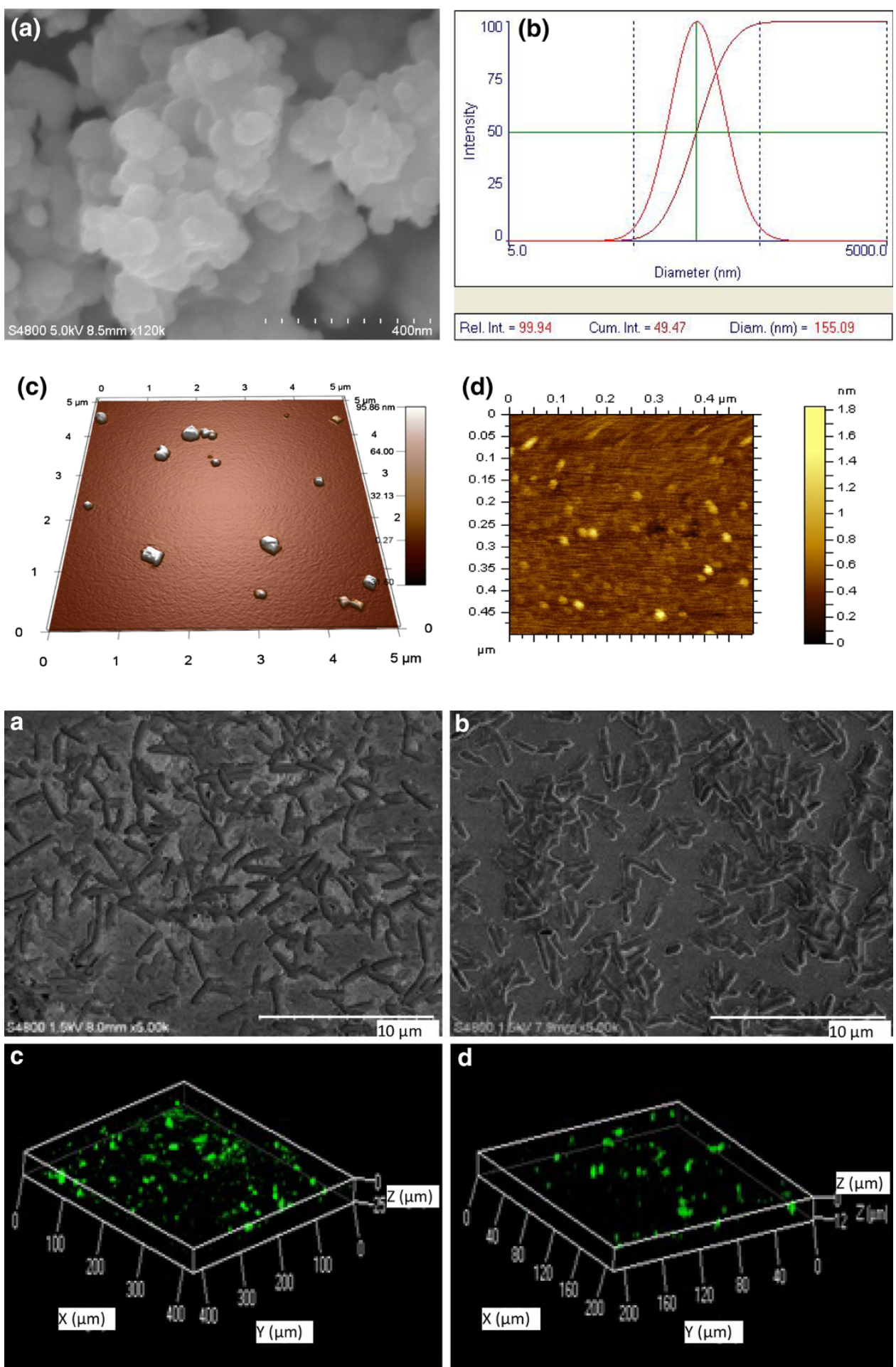

(control), a web-like mass underneath the cells was observed, a typical indication of biofilm structure (Fig. 3a), whereas, for MSNs treated sample, exposed cells with significantly diminished biofilm underneath are observed (Fig. 3b). The diminished biofilm in MSN-treated $P$. aeruginosa was not due to the inhibition of the growth of planktonic cells as the number of planktonic cells in the
MNS-treated cells was nearly same as in control. When we assayed the number of planktonic cells in MNS-treated samples and control, it was nearly equal, approximately $2.3 \times 10^{7}$ cells $/ \mathrm{mL}$. Confocal scanning laser microscopy (CSLM) analysis also confirmed impedance in biofilm formation in the presence of MSN (Fig. 3c, d). Under CSLM, biofilms were seen with patches of fluorescence 
(Fig. 3c), a typical of biofilm. However, in the presence of MSNs (Fig. 3d), the fluorescence was spatially distributed, indicating truncated formation of biofilm (decrease by about $40 \%$ ). In addition, shrinkage in depth of biofilm after MSNs treatment, in comparison to control, can be clearly observed. In comparison to control, the shrinkage in the depth of biofilm was about $12.5 \mu \mathrm{m}$ (SD 0.05).

Various nanoparticles have been reported as agents inhibiting formation of biofilm; however, intriguingly, most of these nanoparticles displayed this property owing to inhibition of cell growth (Hetrick et al. 2009). However, our MSNs impede formation of biofilm in $P$. aeruginosa without actually disrupting bacterial cells or their function (FESEM evidences in Fig. 3a, b). The possible reason for such behavior would be the inhibition of quorum sensing (QS) phenomenon. The QS is a phenomenon in which organisms tend to communicate with each other by secreting a sense molecule into the surrounding medium. When the cell density of $P$. aeruginosa reaches critical level, they tend to form biofilm. Nevertheless, we speculate that MNSs somehow interfere in this QS phenomenon, and thus, inhibit biofilm formation. Growth of the planktonic cells is not inhibited as the concentration used was insufficient to hinder the metabolic reactions inside cells.

Peculiarly, the inhibition of biofilm formation by our MSNs is significant as biofilm protects the pathogenic organisms from drugs and immune system by resisting entry and recognition, respectively. Thus, our MSNs can also be regarded as potential candidate in treating biofilmprotected infections and prevent any bacterial colonization on medical devices implanted in tissues of human being.

\section{Assay on bactericidal activity of MSNs}

MIC (the minimum concentration at which a visual inhibition of growth) of MSNs against B. subtilis and E. coli was 300 and $1,000 \mu \mathrm{g} / \mathrm{mL}$, respectively. Interestingly, the MBC value too was 300 and $1,000 \mu \mathrm{g} / \mathrm{mL}$ against $B$. subtilis and $E$. coli, respectively (Please see Online Resource Figure S1 for graphical data). In comparison to $B$. subtilis, a higher value of MBC (lower activity) of MSNs in $E$. coli is due to the presence of outer layer of lipopolysaccharides. The outer layer of lipopolysaccharides is an extra protective layer in $E$. coli, which, either hinders the entry of MNS or absorbs the free radical generated on the cell wall of these organisms. The antibacterial activity of MSNs is striking especially because there are very few reports pertaining to metal-sulfide nanoparticles exhibiting antimicrobial activity ( $\mathrm{Li}$ et al. 2010; Yamamoto et al. 1999) and none for MSNs.

In order to probe the possible bactericidal mechanism of MSNs, we carried out the quantitative determination of ROS generation in B. subtilis and E. coli cells treated with by fluorescence microscopy and spectrofluorometry (Fig. 4). During this assay, hydrophobic $2^{\prime}, 7^{\prime}$-dichlorfluorescein-diacetate (DCFH-DA) molecules, which readily penetrate cellular membranes, are hydrolyzed by intracellular esterases to yield DCFH, a non-fluorescent compound; DCFH is then oxidized by ROS to fluorescent compound, $2^{\prime}, 7^{\prime}$-dichlorofluoroscein (DCF). A relative lower generation of ROS in case of E. coli in comparison to B. subtilis in the presence of MNS particle is due to presence of outer envelope in $E$. coli (Fig. 4a). As higher reportier of ROS is generated inside $B$. subtilis, we decided to continue further studies with $B$. subtilis. The generation of ROS in cells of $B$. subtilis was corroborated by investigating the specific activities of redox enzymes, superoxide dismutase (SOD), and catalase (CAT). SOD is the first enzyme to interplay in antioxidant mechanism that catalyzes the dismutation of superoxide anion radical $\left(\mathrm{O}_{2}{ }^{-}\right)$into oxygen and hydrogen peroxide. An increase in the specific activity is an indicator of increase in the biosynthesis of enzyme. In the present study, specific activity of SOD for samples treated with MSNs has enhanced from 0.88 (control) to $3.02 \mathrm{IU}$, a 3.45-fold increase (Fig. 4b). A 3.45-fold increase in specific activity is the clear indication of generation of $\left(\mathrm{O}_{2}{ }^{-}\right)$inside the cells of $B$. subtilis which has also been reported as the mechanism of tolerance to oxidative stress by $\mathrm{TiO}_{2}$ in marine abalone, i.e. Haliotisdiversicolor supertexta (Zhu et al. 2011). CAT is an important cellular defense, catalyzing the conversion of hydrogen peroxide $\left(\mathrm{H}_{2} \mathrm{O}_{2}\right)$ to water $\left(\mathrm{H}_{2} \mathrm{O}\right)$ and molecular oxygen $\left(\mathrm{O}_{2}\right)$. Since there was no change in the activity of CAT in the presence of MSNs in B. subtilis (Fig. 4c), the antibacterial activity can be linked with accumulated $\mathrm{H}_{2} \mathrm{O}_{2}$ - the dominating species in antibacterial action against various bacteria (Zhang et al. 2007; Stoimenov et al. 2002).

Reported studies on interaction of nanoparticles with bacterial cells have suggested two main possible reasons for antibacterial activity: (1) generation of ROS (Dwyer et al. 2009) attacking the cytoplasmic membrane of bacteria and rupturing the cells and (2) disruption and disorganization of membranes and/or disruption of cellular function due to deposition/accumulation of nanoparticles on surface of bacteria, in the cytoplasm or in the periplasmic region ( $\mathrm{Nel}$ et al. 2009). Therefore, in order to test first hypothesis, FESEM images of the cells were captured (Fig. 4h-k) during ROS generation. However, FESEM images corresponding to B. subtilis (Fig. 4i) and E. coli (Fig. 4k) indicated that there was no rupture of cells, and cell morphologies remained intact like corresponding controls (Fig. 4h, j), in turn, ruling out possible rupture of the cells by ROS (Su et al. 2009). Transmission electron microscopic (TEM) observation of cells of model organism further corroborated FESEM results that there is no cellular rupture (an insert in Fig. 4h, i). Thus, we conjecture that generated ROS act on B. subtilis and E. coli by yet unknown mechanisms of 

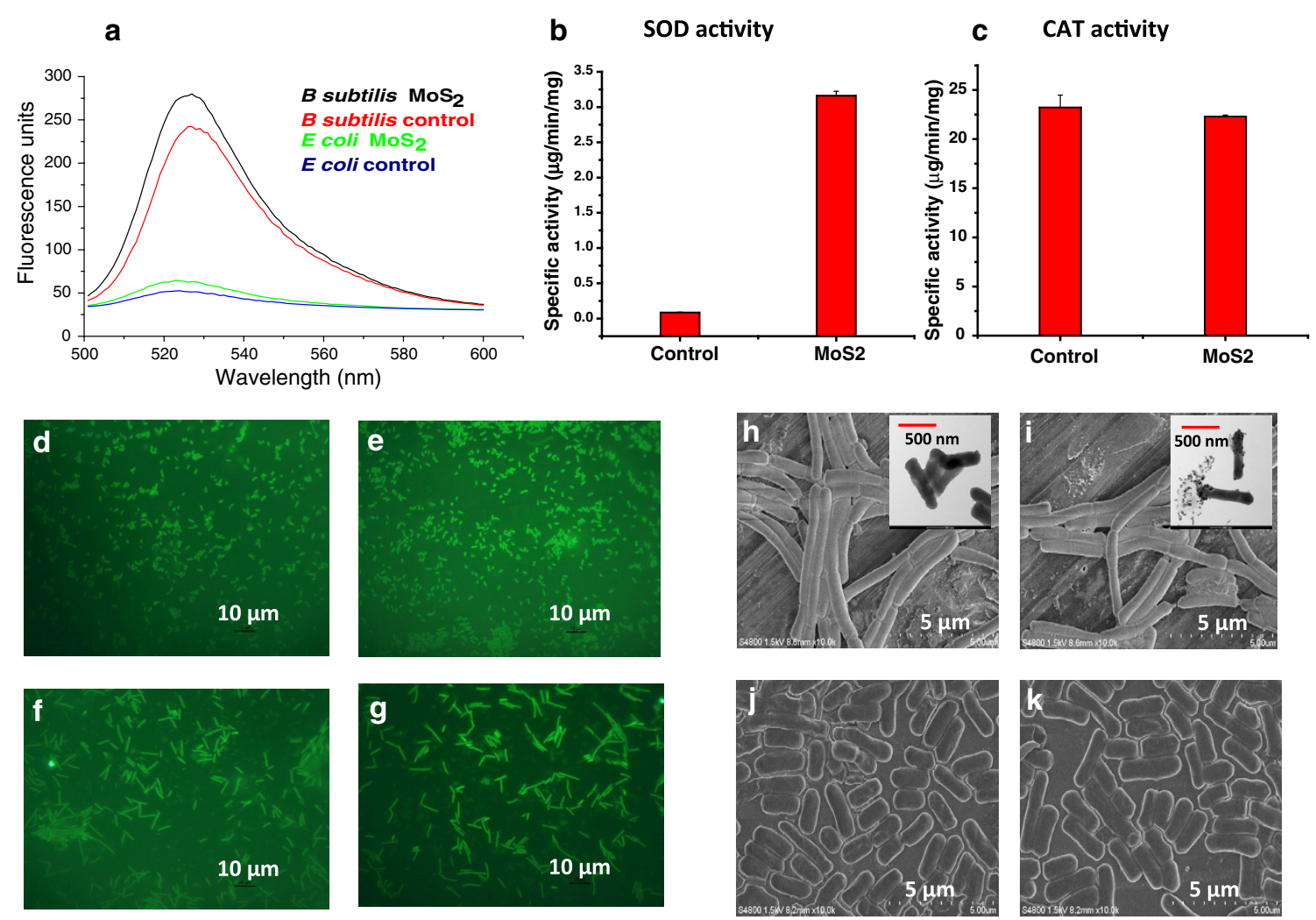

Fig. 4 Investigation of the antimicrobial action, redox enzyme activity and detection of intracellular ROS generation: a quantitative measurement of ROS generation for E. Coli and B. Subtilis. The specific activities of $\mathbf{b}$ super oxide dismutase (SOD) and $\mathbf{c}$ catalase (CAT) of B. subtilis in the presence of MSNs. In the presence of MSNs, there was an increase in the SOD activity by about fourfold over control, although the CAT activity remained the same. FESEM

images of B. subtilis $\mathbf{d}$ control and $\mathbf{e}$ treated and E. coli $\mathbf{f}$ control and $\mathbf{g}$ treated for determination of cell morphology during ROS generation. Fluorescence microscopy images using $\mathrm{H}_{2}$ DFFDA staining for control. $\mathbf{h} B$. subtilis and $\mathbf{j} E$. coli showed less fluorescence and for MSNs treated. i B. subtilis and $\mathbf{k}$ E. coli, a green fluorescence was detected

disruption of cellular function (most probably via damage to DNA, lipids, or proteins instead of cell wall rupture) in stark contrast with antimicrobial action of various nanoparticles as comprehended in Fig. 5. It may be noted that MBC values for B. subtilis and E. coli (at 300 and $1,000 \mu \mathrm{g} / \mathrm{mL}$, respectively) after MSNs treatment in the present study seems higher since we used complex media for assaying antimicrobial and antibiofilm activity. We preferred a complex media because organisms in the environment often encounter a complex nutritional source, and we felt that mimicking the condition of environment would best describe the antimicrobial and antibiofilm assays. A comparison about the reported antimicrobial activities of various nanomaterials against various microorganisms vis-à-vis the present work is presented in Fig. 5. However, in comparison to various reports on nanostructures of $\mathrm{Ag}, \mathrm{Pd}, \mathrm{Fe}-\mathrm{Pt}, \mathrm{TiO}_{2}$, $\mathrm{ZnO}, \mathrm{MgO}, \mathrm{CuO}$, etc., the MIC and MIB values in present study are low (Peng et al. 2002; Xie et al. 2011; Stoimenov et al. 2002; Morones et al. 2005; Ruparelia et al. 2007; Maenosono et al. 2007; Tsuang et al. 2008; Reddy et al.

2007; Heinlaan et al. 2008; De Windt et al. 2006; Lyon et al. 2005). Besides, they exhibit biofilm inhibition. Furthermore, noble metal such as Ag, which emerged as one of the best studied nanoscale inorganic antimicrobial agents (Morones et al. 2005; Ruparelia et al. 2007), may have limited applications due to its higher cytotoxicity. On the other hand, the cytotoxicity studies of MSNs on Hela cell lines confirmed that MSNs are nontoxic (Fig. 6). When the cells of Hela were treated with MNS particles, and assayed for metabolic activeness as a measure of cell number, we found that the metabolic activity in MNS-treated cells were nearly same as in control, indicating that they are nontoxic and, therefore, can be deemed as biocompatible. Similarly, under microscope, control cells were all adhered, uniform and confined to monolayer, a typical of healthy cells, similar to MNStreated cells, (black clusters are the aggregated MSN on cells in the supplementary image S1). Our cytotoxicity data correlate with previous report on MSN (Wu et al. 2011) as a biocompatible material making it comprehensible choice as an antimicrobial agent. 
Fig. 5 Comparative illustration showing the antimicrobial effect of different inorganic nanoparticles and our MSNs on various gram-positive and gram-negative bacteria

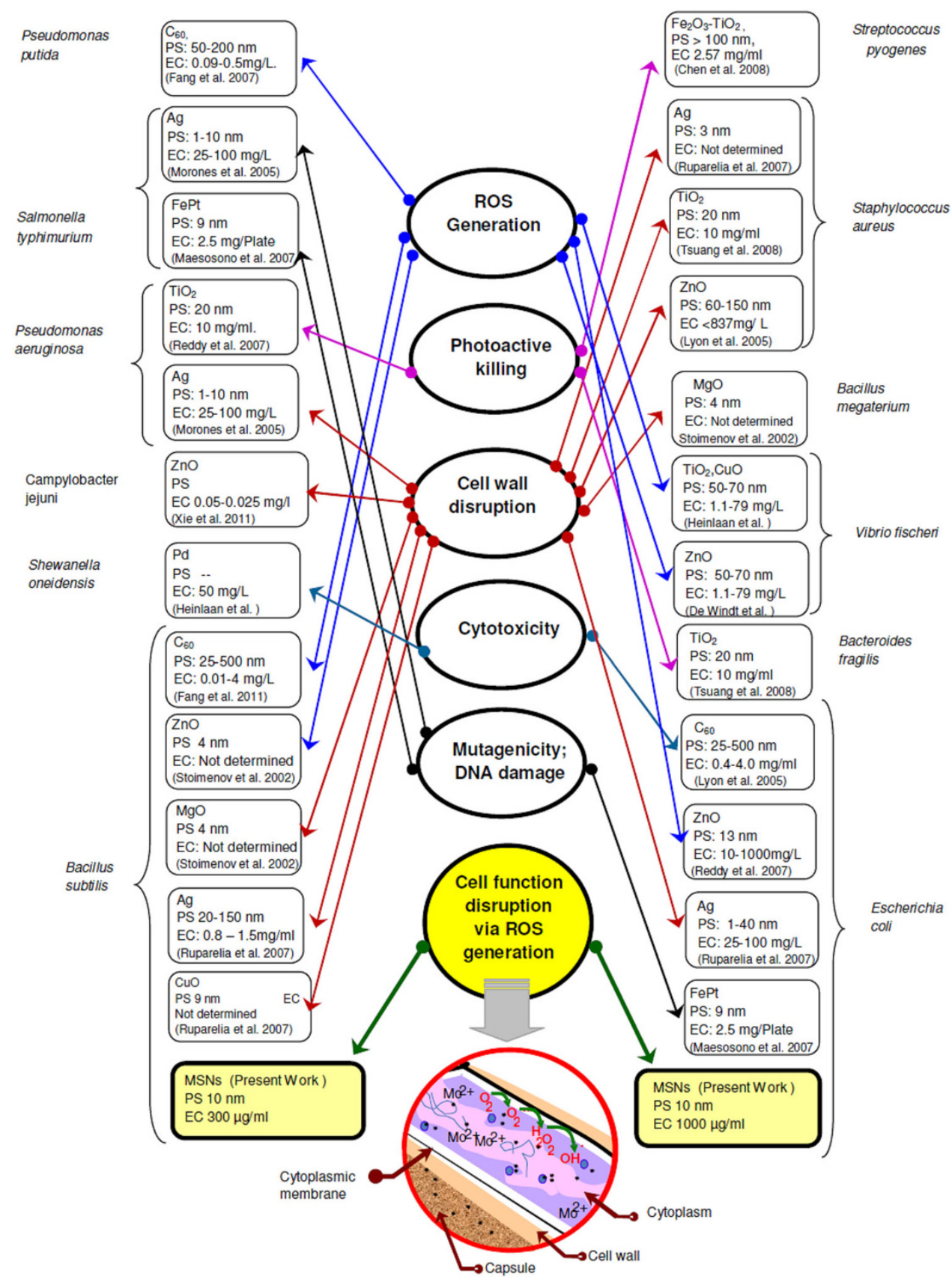

\section{Conclusions}

Bacterial resistance to conventional medical antibiotics based on organic molecules is a serious concern for modern medicine. High prevalence of multidrug-resistant bacteria among bacteria-based infections decrease effectiveness of current treatments and may culminate into contagionrelated deaths. In this context, nanoparticles tend to represent an effective solution for overcoming bacterial resistance. Precisely focusing on fringe benefits of inorganic chalcogenide nanoparticles, we accomplished hitherto unreported synthesis of biocompatible and non- cytotoxic molybdenum disulfide nanostructures at reduced reaction time using facile and 'greener' microwave-assisted solvothermal route with the aim to study their antimicrobial attributes. The formulation containing MSNs demonstrated biofilm inhibition effect (detected using confocal microscopy and FESEM) which enhances the versatility of its applicability. Moreover, by quantitative determination of MIC and MBC, we established the primafacie antibacterial property of our MSNs. We probed the possible mechanism of the antibacterial activity by detecting and measuring ROS, analyzing the change in enzymatic activity of redox enzymes (SOD and CAT) and 

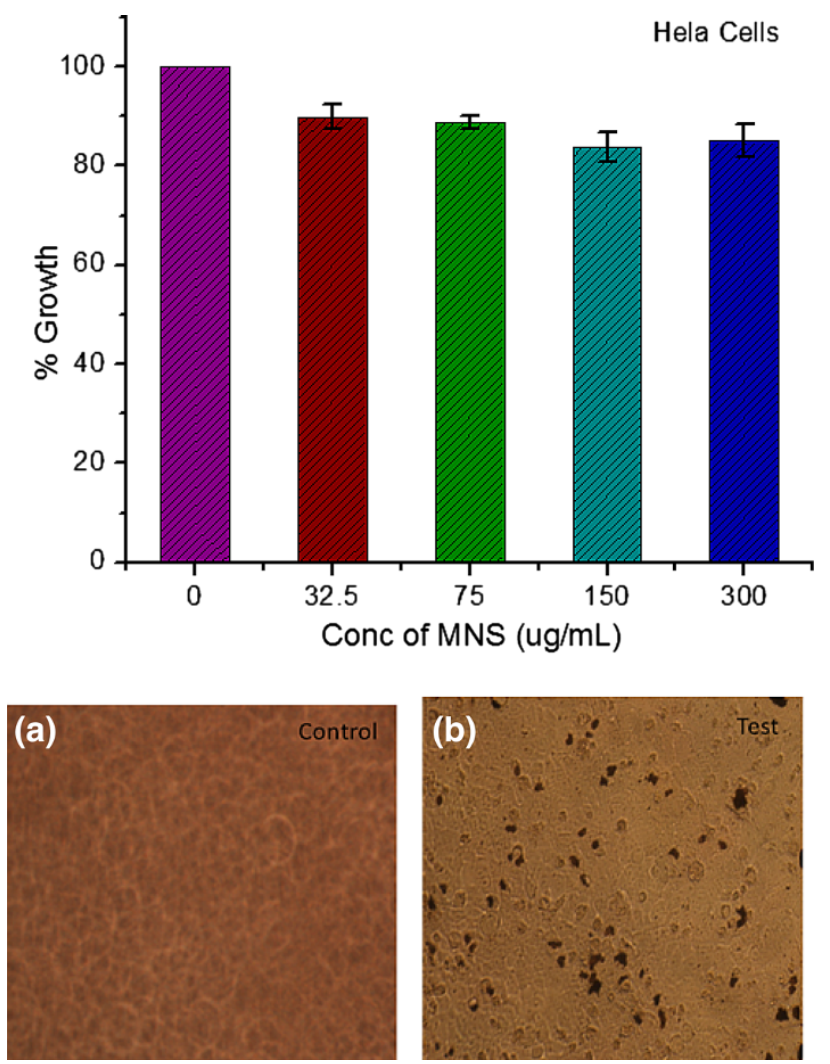

Fig. 6 The cytotoxicity study of the MSN against HeLa cell. The MTT assay on Hela cells in the presence of MNS particles shows a negligible decrease in percent growth, indicating non-cytotoxicity of MNS $(n=3)$. Also, observation of Hela cells in the presence of MNS particle shows uniformity of cells. The black spots in sample b are the aggregations of MNS particles. a Control cells and $\mathbf{b}$ cells treated with MSNs

also by observing the morphological images using fluorescence and electron microscopy. Interestingly, we could realize antimicrobial action by the disruption of cellular function as against rupture of the cell. Our studies and recent studies on MSNs have shown that cytotoxicity is not a major concern for this class of nanoparticles which makes them a promising candidate for clinical trials in small animals. It is presumed that combining nanoparticles with antibiotics not only reduces the toxicity of both agents towards human cells by decreasing the requirement for high dosages but also enhances their bactericidal properties and such a hybrid approach can potentially overcome nanoparticle toxicity and offer a significant improvement in the design of anti-bacterial agents. Furthermore, combining antibiotics with nanoparticles may restore their ability to destroy bacteria that have acquired resistance to them. Therefore, such drug formulations based on MSNs may have vital and unprecedented applications in pharmaceutical and biomedical industry. Additionally, these formulations can be used for external applications and may be coated on medical devices/apparatus such as catheters and endoscopes to curtail the biofilm formation. Moreover, myriad applications of these nontoxic nanostructures may span areas such as hydrogen generation and storage, photocatalysis, hybrid solar cells, drug storage and delivery.

Acknowledgments The authors are thankful to the Department of Electronics and Information Technology (DeitY), Departmental Research and Development Grant, Department of Biotechnology, and BCUD Grant from University of Pune for financial aid. We also acknowledge the assistance of Mr. Keith Jones of Asylum Research and Dr. Dattatri K. Nagesha, Electronics Materials Research Institute and Department of Physics, Northeastern University, USA, for assistance with AFM measurements. We are obliged to Prof. Venkatesan Renugopalakrishnan, Children's Hospital, Harvard Medical School, USA, and Prof. Sowmya Viswanathan, Newton-Wellesley Hospital, USA, for fruitful discussions and encouragement.

Open Access This article is distributed under the terms of the Creative Commons Attribution License which permits any use, distribution, and reproduction in any medium, provided the original author(s) and the source are credited.

\section{References}

Aebi H (1984) Catalase in vitro. Methods Enzymol 105:121-126 Afanasiev P, Bezverkhy I (2002) Synthesis of $\mathrm{MoSx}_{(5}>\mathrm{x}>6$ ) amorphous sulfides and their use for preparation of $\mathrm{MoS}_{2}$ monodispersed microspheres. Chem Mater 14:2826-2830

Afanasiev P, Geantet C, Thomazeau C, Jouget B (2000) Molybdenum polysulfide hollow microtubules grown at room temperature from solution. Chem Commun 12:1001-1002

Aharon E, Albo A, Kalina M, Frey GL (2006) Stable blue emission from a polyfluorene/layered-compound guest/host nanocomposite. Adv Funct Mater 16:980-986

Anon, National Committee for Clinical Laboratory Standards (NCCLS) (2000) Methods for dilution antimicrobial susceptibility tests for bacteria that grow aerobically, Approved standard, 5 th edn. NCCLS document, M7-A5. NCCLS, Wayne

Applerot G, Lellouche J, Perkas N, Nitzan Y, Gedanken A, Banin E (2012) $\mathrm{ZnO}$ nanoparticle -coated surfaces inhibit bacterial biofilm formation and increase antibiotic susceptibility. RSC Adv 2:2314-2321

Bjarnsholt T, Tolker-Nielsen T, Høiby N, Givskov M (2010) Interference of Pseudomonas aeruginosa signalling and biofilm formation for infection control. Expert Rev Mol Med 12:e11

Chen J, Kuriyama N, Yuan HT, Takeshita HT, Sakai T (2001) Electrochemical hydrogen storage in $\mathrm{MoS}_{2}$ nanotubes. J Am Chem Soc 123:11813-11814

Chen WJ, Tsai PJ, Chen YC (2008) Functional $\mathrm{Fe}_{3} \mathrm{O}_{4} / \mathrm{TiO}_{2}$ core/shell magnetic nanoparticles as photokilling agents for pathogenic bacteria. Small 4:485-489

De Windt W, Boon N, Van den Bulcke J, Rubberecht L, Prata F, Mast J, Hennebel T, Verstraete W (2006) Biological control of the size and reactivity of catalytic $\operatorname{Pd}(0)$ produced by Shewanella oneidensis. Antonie Van Leeuwenhoek 90:377-389

Dwyer DJ, Kohanski MA, Collins JJ (2009) Role of reactive oxygen species in antibiotic action and resistance. Curr Opin Microbiol 12:482-489

Fang J, Lyon DY, Wiesner MR, Dong J, Alvarez PJ (2007) Effect of a fullerene water suspension on bacterial phospholipids and membrane phase behavior. Environ Sci Technol 41:2636-2642 
Foucaud L, Wilson MR, Brown DM, Stone V (2007) Measurement of reactive species production by nanoparticles prepared in biologically relevant media. Toxicol Lett 174:1-9

Giannopolitis CN, Ries SK (1977) Superoxide dismutases: I occurrence in higher plants. Plant Physiol 59:309-314

Heinlaan M, Ivask A, Blinova I, Dubourguier HC, Kahru A (2008) Toxicity of nanosized and bulk $\mathrm{ZnO}, \mathrm{CuO}$ and $\mathrm{TiO}_{2}$ to bacteria Vibrio fischeri and crustaceans Daphnia magna and Thamnocephalus platyurus. Chemosphere 71:1308-1316

Hetrick EM, Shin JH, Paul HS, Schoenfisch MH (2009) Anti-biofilm efficacy of nitric oxide-releasing silica nanoparticles. Biomaterials 30:2782-2789

Imanishi N, Kanamura K, Takehara Z (1992) Synthesis of $\mathrm{MoS}_{2}$ thin film by chemical vapor deposition method and discharge characteristics as a cathode of the lithium secondary battery. J Electrochem Soc 139:2082-2087

Jones SA, Bowler PG, Walker M, Parsons D (2004) Controlling wound bioburden with a novel silver-containing hydrofiber dressing. Wound Repair Regen 12:288-294

Kopnov F, Leitus G, Yoffe A, Feldman I, Panich AM, Tenne R (2006) Electric transport properties and 1H NMR study of the fullerene-like $\mathrm{WS}_{2}$ nanoparticles. Phys Stat Sol 243:3290-3296

Li WJ, Shi EW, Ko JM, Chen ZZ, Ogino H, Fukuda T (2003) Hydrothermal synthesis of $\mathrm{MoS}_{2}$ nanowires. J Cryst Growth 250:418-422

Li Q, Li M, Chen ZQ, Li CM (2004) Simple solution route to uniform $\mathrm{MoS}_{2}$ particles with randomly stacked layers. Mater Res Bull 39:981-986

Li Q, Walter EC, van der Veer WE, Murray BJ, Newberg JT, Bohannan EW, Switzer JA, Hemminger JC, Penner RM (2005) Molybdenum disulfide nanowires and nanoribbons by electrochemical/chemical synthesis. J Phys Chem B109:3169-3182

Li G, Zhai J, Li D, Fang X, Jiang H, Dong Q, Wang E (2010) One-pot synthesis of monodispersed $\mathrm{ZnS}$ nanospheres with high antibacterial activity. J Mater Chem 20:9215-9219

Liu SB, Wei L, Hao L, Fang N, Chang MW, Xu R, Yang YH, Chen Y (2009) Sharper and faster "nano darts" kill more bacteria: a study of antibacterial activity of individually dispersed pristine single-walled carbon nanotube. ACS Nano 3:3891-3902

Lyon DY, Fortner JD, Sayes CM, Colvin VL, Hughe JB (2005) Bacterial cell association and antimicrobial activity of a $\mathrm{C}_{60}$ water suspension. Environ Toxicol Chem 24:2757-2762

Maenosono S, Suzuki T, Saita S (2007) Mutagenicity of water-soluble FePt nanoparticles in Ames test. J Toxicol Sci 32:575-579

Morones JR, Elechiguerra JL, Camacho A, Holt K, Kouri JB, Ramírez JT, Yacaman MJ (2005) The bactericidal effect of silver nanoparticles. Nanotechnology 16:2346-2353

Nel AE, Madler L, Velegol D, Xia T, Hoek EMV, Somasundaran P, Klaessig F, Castranova V, Thompson M (2009) Understanding biophysicochemical interactions at the nano-bio interface. Nat Mater 8:543-557

Nemanič V, Žumer M, Zajec B, Pahor J, Remškar M, Mrzel A, Panjan P, Mihailovič D (2003) Field-emission properties of molybdenum disulfide nanotubes. Appl Phys Lett 82:4573-4575

Peng Y, Meng Z, Zhong C, Lu J, Yang Z, Qian Y (2002) Tube- and ball-like amorphous $\mathrm{MoS}_{2}$ prepared by a solvothermal method. Mater Chem Phy 73:327-329

Radisavljevic B, Radenovic A, Brivio J, Giacometti V, Kis A (2011) Single-layer $\mathrm{MoS}_{2}$ transistors. Nat Nanotech 6:147-150
Rapoport L, Fleischer N, Tenne R (2003) Fullerene-like $\mathrm{WS}_{2}$ nanoparticles: superior lubricants for harsh conditions. Adv Mater 15:651-655

Rapoport L, Fleischer N, Tenne R (2005) Applications of $\mathrm{WS}_{2}$ $\left(\mathrm{MoS}_{2}\right)$ inorganic nanotubes and fullerene-like nanoparticles for solid lubrication and for structural nanocomposites. J Mater Chem 15:1782-1788

Reddy KM, Feris K, Bell J, Wingett DG, Hanley C, Punnoose A (2007) Selective toxicity of zinc oxide nanoparticles to prokaryotic and eukaryotic systems. Appl Phys Lett 90:21390212139023

Ruparelia JP, Chatterjee AK, Duttagupta SP, Mukherji S (2007) Strain specificity in antimicrobial activity of silver and copper nanoparticles. Acta Biomater 4:707-716

Shinde MD, Chavan PG, Umarji GG, Arbuj SS, Rane SB, More MA, Joag DS, Amalnerkar DP (2012a) Field emission and photocatalytic investigations on hierarchical nanostructures of copper doped CdS synthesized by 'kitchen-chemistry' approach. J Nanosci Nanotechnol 12:3788-3798

Shinde M, Patil R, Karmakar S, Bhoraskar S, Rane S, Gade W, Amalnerkar D (2012b) Antimicrobial properties of uncapped silver nanoparticles synthesized by DC arc thermal plasma technique. J Nanosci Nanotechnol 12:887-893

Stoimenov PK, Klinger RL, Marchin GL, Klabunde KJ (2002) Metal oxide nanoparticles as bactericidal agents. Langmuir 18:6679-6686

Su HL, Chou CC, Hung DJ, Lin SH, Pao IC, Lin JH, Huang FL, Dong RX, Lin JJ (2009) The disruption of bacterial membrane integrity through ROS generation induced by nanohybrids of silver and clay. J Biomater 30:5979-5987

Thomalla M, Tributsch H (2006) Photosensitization of nanostructured $\mathrm{TiO}_{2}$ with $\mathrm{WS}_{2}$ quantum sheets. J Phys Chem B110: 12167-12171

Tsuang YH, Sun JS, Huang YC, Lu CH, Chang WH, Wang CC (2008) Studies of photo killing of bacteria using titanium dioxide nanoparticles. Artif Organs 32:167-174

Weir E, Lawlor A, Whelan A, Regan F (2008) The use of nanoparticles in anti-microbial materials and their characterization. Analyst 13:835-845

Wu H, Yang R, Song B, Han Q, Li J, Zhang Y, Fang Y, Tenne R, Wang C (2011) Biocompatible inorganic fullerene- like molybdenum disulfide nanoparticles produced by pulsed laser ablation in water. ACS Nano 5:1276-1281

Xie Y, He Y, Irwin PL, Jin T, Shi X (2011) Antibacterial activity and mechanism of action of zinc oxide nanoparticles against Campylobacter jejuni. Appl Environ Microbiol 77:2325-2331

Yamamoto O, Sawai J, Ishimura N, Kojima H, Sasamoto T (1999) Change of antibacterial activity with oxidation of $\mathrm{ZnS}$ powder. J Ceram Soc Jpn 107:853-856

Zhang L, Jiang Y, Ding Y, Povey M, York D (2007) Investigation into the antibacterial behaviour of suspensions of $\mathrm{ZnO}$ nanoparticles (ZnO nanofluids). J Nanopart Res 9:479-489

Zhu X, Zhou J, Cai Z (2011) The toxicity and oxidative stress of $\mathrm{TiO}_{2}$ nanoparticles in marine abalone (Haliotisdiversicolor supertexta). Mar Pollut Bull 63:334-338 